\title{
On the Reciprocal Mechanism of English as a Lingua Franca Participating in the Re-Generation of Sinitic Culture
}

\author{
Zhengxiang Tang1, Min Wang² \\ ${ }^{1}$ Department of College English, Zhejiang Yuexiu University, Shaoxing, China \\ ${ }^{2}$ School of English, Zhejiang Yuexiu University, Shaoxing, China \\ Email:229192872@qq.com, 59532954@qq.com
}

How to cite this paper: Tang, Z.X. and Wang, M. (2021) On the Reciprocal Mechanism of English as a Lingua Franca Participating in the Re-Generation of Sinitic Culture. Open Access Library Journal, 8: e7612.

https://doi.org/10.4236/oalib.1107612

Received: June 4, 2021

Accepted: July 12, 2021

Published: July 15, 2021

Copyright $\odot 2021$ by author(s) and Open Access Library Inc.

This work is licensed under the Creative Commons Attribution International License (CC BY 4.0).

http://creativecommons.org/licenses/by/4.0/

\begin{abstract}
The spread of English from a foreign language (EFL) to a lingua franca (ELF), underpinned by American culture, Anglophone culture, Western culture and the orientation of cultural universalism within the sphere of China and the Sinitic world, has been producing three linguistic-cultural circles: the outer is ELF and the culture; the superficial is the official Mandarin Chinese as a lingua franca (CLF) that represents the mainstream/dominant culture and political unification; and the inner, the vernacular/indigenous dialects/languages (VDL) that stand for sub/co-cultures and multi-culturalism. The movements, including clash and co-existence, of the three circles have generated two dynamic mechanisms within the re-generative paradigm of Sinitic cultural ecology: one is the assimilative mechanism and the other is the rejective mechanism. The two mechanisms, in turn, have operated among the three circles. The three circles and two mechanisms are functioning and re-shaping the on-going Sinitic cultural morphology. The current linguistic diversity and the dual lingua fracas of English and Mandarin, having caused the current split state of the Sinitic cultural morphology, demonstrate the evolving orientations toward multi-culturalism and universalism.
\end{abstract}

\section{Subject Areas}

Linguistics

\section{Keywords}

ELF, Sinitic Culture, Re-Generative Paradigm, Assimilative Mechanism, Rejective Mechanism 


\section{Introduction}

As a premise, it is necessary, from the current mainstream viewpoint in China, to define the relationship among English as a foreign language (EFL), the Anglophone culture and the pillar of global culture/civilization. English as a lingua franca (ELF)/the current universal language reflects the powerful projection of the Anglophone culture (now mainly American culture, roughly the West culture) throughout the world. The essence of ELF represents the trend of cultural universalism, or exactly Westernization, although as an adversary trend, the spread of ELF might be challenged by multi-culturalism. Compared with ELF, official Mandarin Chinese historically was and currently is a lingua franca (OMCLF, or shortly CLF) within the sphere of China and the Sinitic world.

The Sinitic culture has been suffering from birth pangs after Western culture broke in. The traditional Chinese cultural morphology was constituted by two dimensions: the dominant/mainstream culture that was symbolized by official Mandarin Chinese as a lingua franca, and the subcultures that were shown as the vernacular/indigenous dialects and languages (VDL). From the 1840s onward, the West culture from the strong societies that were typically represented by English from a foreign language to a lingua franca, banged into the original structure of Sinitic culture. The on-going split of Sinitic culture has been re-generating a new morphology. In the erratic and nonlinear course of rebuilding Sinitic cultural ecology interwoven by the three linguistic-cultural dimensions, the underlying structure in the specific paradigm of the re-generative mechanism will be probed in the light of Chaos Theory.

\section{Three Linguistic-Cultural Circles within the Chinese Cultural Ecology}

According to the distance to the Sinitic cultural roots, three linguistic-cultural circles have been discerned within the structure of the Sinitic cultural ecology: the outer is ELF and the culture; the superficial is the official Mandarin Chinese as a lingua franca (CLF) that represents the mainstream/dominant culture and political unification; and the inner, the vernacular/indigenous dialects/languages (VDL) that stand for the subcultures and multi-culturalism (see Figure 1).

\subsection{The Outer Circle: The Transplanted English as a Lingua Franca and the Cultural Universalism}

The trend of English and the relevant cultures planting in China demonstrates acceleration. In 1637, English touched China with British traders arriving in Macao and Canton (present Guangzhou), ([1]: p. 157) as such, English as a lingua franca was used between British traders and the Cantonese-speaking Chinese people; during the business process, Chinese Pidgin English was produced naturally ("Pidgin" at Dictionary.com). After regulating English as the main foreign language in the educational system in 1982, [2] the current estimates of English learners in China reach to $300-500$ million, ([3]: p. 56) which implies 


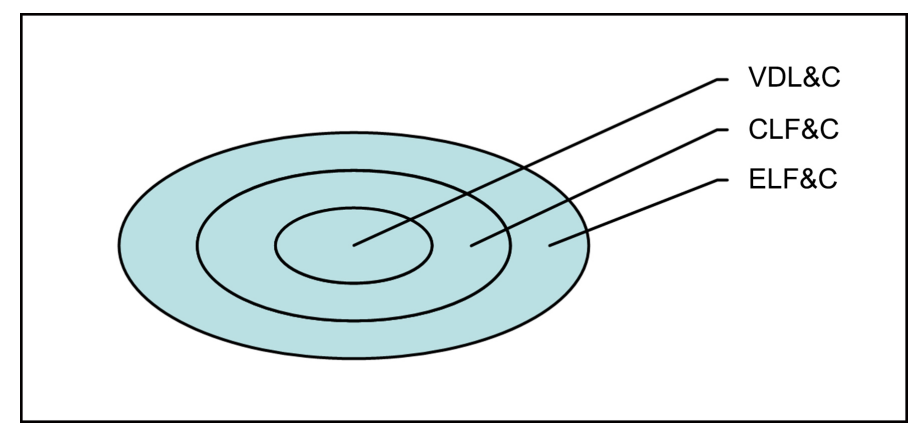

Figure 1. The three lingual-cultural circles within Sinitic culture. ${ }^{\star}$ VDL\&C: the vernacular/indigenous dialects and languages and the subcultures; ${ }^{\star}$ CLF\&C: official Mandarin Chinese as a lingua franca and the official culture; ${ }^{\star}$ ELF\&C: English as a lingua franca and the planted cultures; (source: the author's own work).

the total amount of Chinese people who learned and are learning English, reaches approximately to 1 billion at present.

Strictly, the Chinese mainland formally accepted English as the main foreign language for the purpose of its procedure of modernization on the social background of the New Stage (since 1978 onward) internally and on the background of the accelerating process of globalization externally. In this sense, English within the sphere of the Chinese mainland owns its double identities: the main foreign language (EFL) that represents the culture of Anglophone and symbolizes the strong society; and the global lingua franca (ELF) that delegates West civilization as the cultural universalism. In order to merge in the international community, the People's Republic of China (PRC) had to deal with the West world because the international community almost equals the West world ([4]: p. 184).

Several notable phases of English spreading in China could be observed clearly: the first phase is from the two Opium Wars to the founding of the Republic of China (POC) in 1912, the second, to the establishment of the People's Republic of China (PRC) in 1949, the third, to implementation the Reform and Opening policy in 1978, and since then on, the fourth. The fourth phase, namely, the current one, demontrates complex orientations toward English and the culture: English language and some dimensions of the culture would be accepted while the other dimensions of the culture, especially Christianity and the political culture, would be expelled. In the process of the above phases, the basic attitudes of Chinese people toward EFL and ELF converted violently: during the first phase, it is reluctant to receive the English language and the culture; in the second phase, accepted the linguistic cultural entity actively and systematically; in the third, they were repelled completely; and in the fourth, fell to the paradox of admiration mixing with alert and even with hostility.

\subsection{The Inner Circle: The Vernacular/Indigenous Dialects and Languages Representing the Natural, Innate and Diverse Subcultures}

The indigenous dialects of Chinese might vary even more than that within Ro- 
man languages ([5]: p. 187). It is estimated that there are hundreds of mutually unintelligible varieties of Chinese ([6]: p. 72). However, the rate of change in mutual intelligibility varies immensely depending on the regions. For example, the Northern varieties, which are the basic source of Mandarin, spoken in all three north-eastern Chinese provinces are mutually intelligible, but in the province of Fujian, where Min varieties predominate, the speech of neighbouring counties or even villages may be mutually unintelligible ([5]: p. 188). The Chinese term Fangyan is used for all Chinese varieties, which are customarily named after the relevant areas, provinces and sub-varieties, cities. To avoid leading to misinformation in the West, "Fangyan" could not be translated into English as "dialect", which in its normal English usage suggests mutually intelligible varieties of a single language. Hence, John DeFrancis suggests "regionalect" for the mutually unintelligible varieties of Chinese, leaving "dialect" for the mutually intelligible sub-varieties ([7]: p. 57). Mair suggests "topolect" instead of that [8].

Prior to the ELF linguistic-cultural impact on China, the diversity of Chinese languages, including Han language and the other languages within the sphere of China (minor ethnic languages at present), reflected the diversity of the Sinitic co-cultures. Perhaps, the tree model and the wave model (originally presented by Johannes Schmidt) in historical linguistics might illustrate the evolving pattern of the Han language and the Sinitic languages; and underlying the historical process, the two linguistic models ought to be adapted to the evolution of Sinitic culture. Ethnocentrism or exactly, Sinocentrism contains the traditionally hierarchical system of Sinitic linguistic-cultural diversity. The northern topolect and the cultural centre, originated in the Central Plain, belonged to the top class; the other indigenous varieties and sub-varieties of Han language occupied the second class; and the minor ethnic languages and the cultures, which were subjected to the Chinese empires, belonged to the third class; the fourth, outside this circle, were the tributary states; the bottom was beyond the circle, regarded as "uncultivated lands" (literally translated from Huawai Zhi Di), such as Taiwan (Formosa) in the period of Qing Dynasty [9]. Roughly, it often took the form of viewing the ancient Sinitic culture as one of the most advanced civilizations in the world, and those external ethnic groups or foreign nations as being uncivilized to various degrees, a distinction known in Chinese as the Hua-Yi distinction ([10]: p. 544).

VDL and the diverse subcultures dominated by the ruling class constituted the innate varieties of the Sinitic cultural ecology. Or simply, the Sinitic culture could be divided into two layers: the upper was the dominant northern variety of Han language and Confucianism mixed with Taoism as well as Buddhism later; the lower, the other varieties of Han language and the languages of the minorities and the relevant subcultures. However, the traditional Sinitic linguistic-cultural ecology with the two layers and the hierarchical circles was suddenly broken by English and the other western languages and the cultures, or Xixue (the West Studies). The Sinitic varieties of the languages and the subcultures that represent 
multiculturalism encountered dual pressures: the interior, Mandarin as a lingua franca and the dominant culture; and exterior English as another lingua franca and cultural universalism, or realistically, Westernization.

\subsection{The Superficial Circle: Chinese as Lingua Franca Standing for National Language and the Monoculturalism}

For the purpose of this article, it is necessary to point out that the official Mandarin Chinese as a lingua franca (CLF) is, in fact, the institutional (even constitutional) national language used within the sphere of PRC, especially, being regulated by the laws and the Party's policies, and being adjusted and managed by the governments. The key points of the connotation emphasize: 1) the function as a common language used among the Sinitic cultural circles; 2) the orthodoxy of political culture; 3 ) on the social/cultural top-level status or supremacy; and 4) enforcing use within the sphere of PRC. Shortly, the essence of CLF lies in its institutionalism, differentiating from the generative characteristics of the other varieties of Chinese language and the other official languages.

The history of Mandarin was, generally, interwoven with that of the dominant/mainstream culture; specifically tied to and advocated or ruled by the regimes in different periods. Granted, Mandarin was based on the northern variety of Han ethnic language, which only encompassed the political and cultural centre; by that, Mandarin could expand to extensive areas. Anyway, the northern variety itself never acted as Mandarin as some experts believe in ([11]: pp. 63-64). The earliest text recounting the dialectal variations from the Spring and Autumn period (722 - $479 \mathrm{BC}$ ) was found; in that, the Zhou royal court defined the standard speech ([5]: p. 183). Later, the Qieyun rhyme book (601AD) set out to define a standard pronunciation for reading the classics ([12]: pp. 116-117). The standardized diasystem, known as Middle Chinese, is believed on the basis of the reading traditions of the northern and southern capitals ([5]: pp. 24-25). To Ming and Qing dynasties, for the purpose of practice, officials carried out the administration of the empire using a common language, known as "Guanhua" (literally, the official or the governmental language) ([5]: p. 136). All the standardized, official language as a lingua franca is Mandarin that represented the dominant culture, even without exceptions in the periods of Jin kingdom, Yuan and Qing dynasties, the ruling class belonged to the ethnic minorities.

Although in the 1930s, the government of the Republic of China adopted a standard national language, the written standard taking Baihua (written vernacular Chinese) instead of Wenyan (Literary Chinese) which was based on the northern variety and the pronunciation cantered on the Beijing dialect ([12]: pp. 3-15). The official, legislated status still remained. After simplifying the Chinese characters $($ Hanzi), the standard national language was inherited, used as a lingua franca (known as modern Han language, or Putonghua, literally "common speech") among the 56 ethnic groups, there exist 298 living languages according to the Ethnologue [13]. CLF was produced and issued and spread (not generated 
naturally) by the political powers (not only by the academic authorities); and thence, interweaving Chinese dominant/mainstream culture, CLF constituted the upper layer that restricts all minor ethnic languages and all varieties and dialects of Han language.

\section{The Assimilative Mechanism of ELF, CLF and VDL among the Re-Generative Paradigm of Sinitic Cultural Ecology}

Underlying the regenerative paradigm of Sinitic cultural ecology, there is an assimilative mechanism consisting of three circles. The different patterns of their assimilative combinations (see Figure 2) have generated three constructive orientations: 1) reinforcing the central status of CLF as the national language in PRC; 2) stimulating VDL to the direction of linguistic and cultural diversity within the sphere of the Sinitic world and around the globe; and 3) accelerating the spread of ELF not only as language but also as cultural values.

\subsection{Xinhua Style Chinglish: The Coupling of ELF with CLF}

The combination of ELF and CLF is one variation of Chinglish: Xinhua Chinglish, which is based on the Xinhua News Agency [14]. The instances could be traced back to "paper tigers" (Zhi Laohu), "running dogs" (Zou Gou) and "Long Chairman Mao" in the 1940s and 1950s; the typical examples, on the discourse layer, demonstrated bureaucratic tone, or the Mandarin (speech of the officials) style, may be observed at the very beginning of a speech or an article, from "Under the leadership of the Party, Chinese people..." to the updated "Chinese Dreams". Xinhua Chinglish belongs to both categories of Chinglish: instrumental and ornamental. "Instrumental Chinglish is actually intended to convey information to English speakers" and "Ornamental Chinglish is born of the fact that English is the lingua franca of coolness" [15].

By means of Xinhua Chinglish, English and Mandarin take the support from each other to reinforce the instrumental and the ornamental functions respectively. On the one hand, the mainstream culture of PRC borrowed the power of the US entering the UN in 1972 and later linked to the West prevalently since 1978. As such, Xinhua Chinglish can project Mandarin and Chinese mainstream

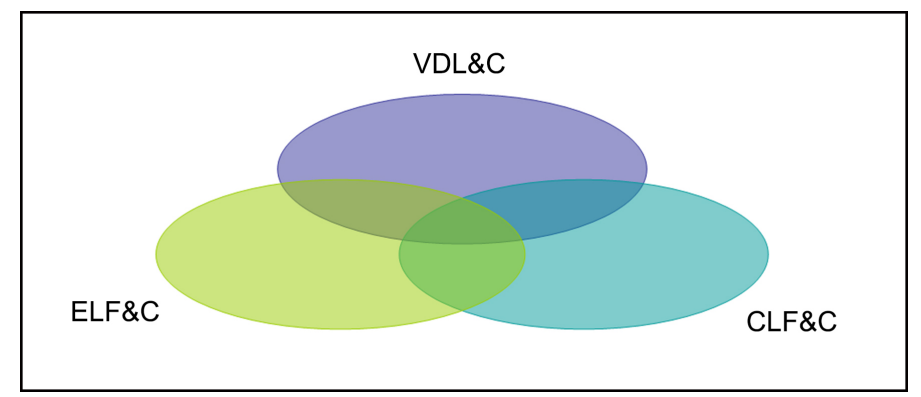

Figure 2. The assimilative mechanism within the cohesive ecology of Sinitic culture. ${ }^{\star}$ The overlap parts represent the 2 or 3 mixed, or melted lingual-cultures respectively. (Source: the author's own work). 
culture to the international community within which Xinhua Chinglish spread as a variant of Englishes. In return, the influence of Mandarin and Chinese mainstream culture in the world may reinforce the authority and orthodoxy of them in the world. On the other hand, since English was accepted as a main foreign language on the Chinese mainland in 1982, the Anglophone and the West cultures following ELF have spread within the sphere of Red China. At least, the majority of Chinese people have no longer regarded the Anglophone and West communities as an evil world.

In the course of the combination, CLF took advantage of the authority of EFL and adapted to the high context culture in the international (the West) community; and EFL utilized the power of CLF and adapted to the high context of the political culture in PRC. Having learned by 1 billion people, including all the young in China, both English and Mandarin as lingua fracas, accompanied with Chinese mainstream culture and global universalism, have created the preliminary condition of reshaping the current cultural morphology and regenerating a new cultural ecology. The coupling achievement of English and Mandarin is Xinhua English that converted EFL into one variant of ELF.

\subsection{Chinese Pidgin English: The Coupling of ELF with VDL}

The adaptation of ELF to VDL in China, at the very beginning, produced the other type of Chinglish: Chinese Pidgin English (CPE). CPE was spoken firstly in the areas of Macao and Canton (Guangzhou), later spreading north to Shanghai by the 1830s, ([1]: p. 256) and then, to regions beyond the Chinese Coast. In those writings of Western travelers in China are scattered reports of the pidgin being spoken farther inland, such as in Chungking (Chongqing) and Hankow (Hankou), and farther north, in Kyong Song and even Vladivostok. [16] CPE was also taken beyond China, shaping/influencing Nauruan Pidgin English, [17] Australian English and other pidgins, [18] even California Chinese Pidgin English [17].

Although some believe that ELF carries the culture and language of its speakers, [19] others hold that it is a neutral and culture-free tool [20]. Recent discussions demonstrate that the interactively cultural and linguistic background as a factor influences the language performance [21]. As such, ELF is multicultural rather than culture-free. In this view, ELF encountering VDL can drive Chinese linguistic and cultural diversity and further lead to its renewal. A relevant example is Singaporean culture as a variant of Sinitic culture, which is an outcome of the coupling Cantonese and Hokkien with ELF and the others, or importantly, of the coupling of the related cultures without institutional control by Mandarin. The neutrality of ELF, in the case, retains and stimulates the variety of Sinitic subcultures and the fusion with the target culture. That is the substratum of cultural tolerance and multiculturalism; or, exactly, two cultural tendencies can be caused: de-Sinocentrism and cultural self-identity. That is one aspect of regenerative mechanism in the Sinitic cultural ecology. 


\subsection{CLF as a National Language: Re-Enforcing the Alliance with VDL when Facing to the Global ELF}

In the long history of Sinitic culture and languages, the ally of the Confucius ideology and the regimes of different dynasties (including the Manchu Qing) forcibly dominated forcibly the lingual-cultural morphology of China, whereby the supremacy of Sinitic culture and Mandarin as a lingua franca was sustainable and expanded. In 1932, Mandarin acquired the legal status of national language in ROC and actually was retained by PRC, named "modern Han language" or "common speech" or "standard Chinese". That is the current CLF. The status of the national language was even guaranteed by the Constitution of PRC (1982) and a series of material, spiritual and institutional systems, which apparently differ from the other official languages. Both the Three People's Principle of ROC and the socialism of PRC belong mainly to the Western culture that transplanted forcibly into the ground of China after the violent clash between the Sinitic culture and the Western. Nevertheless, the cohesion of the Sinitic culture and CLF owning the status as the national language has still been maintained legally, forcibly and systematically. In other words, the assimilative mechanism among CLF and VDL lies in their interactive relationships of "nurture vs. nature", or "superstructure vs. infrastructure".

Roughly, in the period of pre-ROC, Mandarin and Sinocentrism dominated the Sinitic languages and cultures. Since the establishments of POC and PRC onwards, distinctive subcultures of the West civilization have gradually leaked into Chinese mainstream culture. Related to that, English as the main foreign language was legally confirmed, emphasized by a set of linguistic policies and measures; and following the advent of schooling popularized and advanced, ELF in the Sinitic world is actually coming. Thus, the compatible mechanism of CLF and ELF lies in the powerful cultures underpinning them respectively: the northern subcultures behind Mandarin within the sphere of China and the Anglophone culture or mainly American culture following English around the world.

\section{The Rejective Mechanism of ELF, CLF and VDL among the Re-Generative Paradigm of Sinitic Culture}

Adversary to the assimilative mechanism, a rejective mechanism also exists underlying the current Sinitic culture (see Figure 3). Each of the three portfolios within the three linguistic-cultural circles has been repelling the others, causing inadaptation of modern Sinitic culture.

\subsection{CLF versus ELF + VDL, Sinicization or De-Sinicization?}

Two trends of De-Sinicization and Sinicization among different VDL regions in the Sinophone world reflect the rejective mechanism: CLF versus ELF + VDL. CLF, by means of political power, spread toward each corner in PRC. At the same time, English and the culture, being viewed as capitalist ideology, were rejected. Fundamentally, the hostility of ELF and CLF manifested the political 


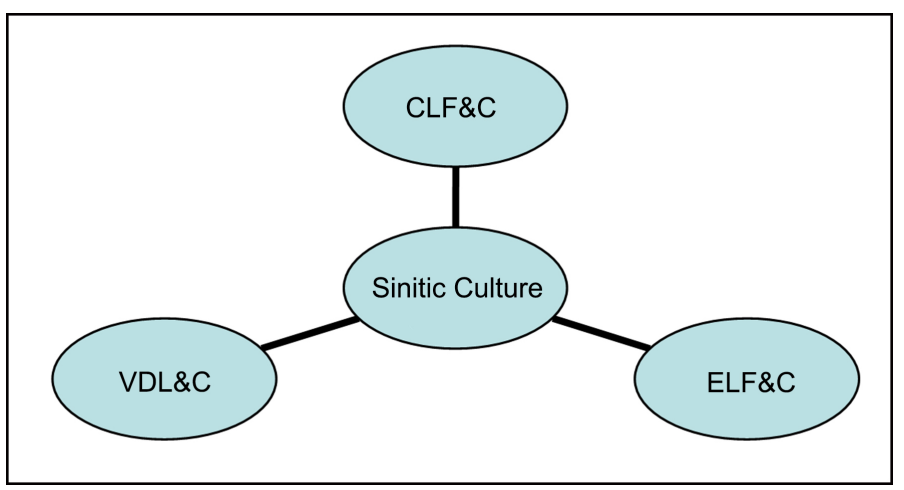

Figure 3. The rejective mechanism within the inadaptive Sinitic culture. (Source: the author's own work).

culture in the Maoism era in PRC. Anyway, to some degree, the tension between ELF and CLF was gradually relaxed in the post Maoism era. The counterbalance or collision of ELF and CLF in PRC still existed that could be seen from the two sides. CLF and the Chinese mainstream/dominant culture have always controlled, at least restricted the spread of English as a foreign language, fearing the spread of capitalist values. Thus, ELF, which is not as the relevant cultural carrier, but just as a communicative tool, was emphasized. In other words, the neutral tool of ELF was accepted by PRC while EFL, as a part of the culture, was supervised. Meanwhile, English and the culture countered the controls by the power of supremacy in the world. The competition between the two lingua fracas and the competition between the two cultures behind them respectively can be discerned in times.

PRC strictly carries out the language policy of linguistic purism. According to the classification of puristic orientations made by George Thomas, ([22]: p. 108) CLF has been purified by two approaches: reformist purism and patriotic purism. Reformist purism generally is to break the bonds with the past; CLF, further, has implemented radical policy, or at times exactly, the revolutionary purism that not only wanted to break the bonds with traditional Chinese culture, but also restricted and swept the co-cultures linking to the vernacular languages of the ethnic minorities and of the regional sub-cultures connecting with the varieties of Chinese dialects. As a result, CLF was molded as a strong feature, Xinhua style CLF, which is the basis of Xinhua English. Xinhua CLF posed different characteristics in different phases: Yan'an in 1940s, the Great Leap in 1950s, the Cultural Revolution 1960-70s and thereafter, the Reform and Opening-up. In short, the present Chinese mainstream culture is a new version of Xinhua styles. In this case, patriotic purism is to prevent the international linguistic-cultural imperialist and Westernization and the important carrier: English as a foreign language. The spread of English has always been monitored, specifically in the educational system: ELF is welcome and EFL is supervised. The purified course borrowed the name of Sinicization.

Contrast to the strong movements of Sinicization, the De-Sinicization appears 
weak and intermittent. The desinicized Han people who adopted steppe culture existed as early as dating back to sixth and seventh centuries A.D., ([23]: p. 248) especially, in the periods of Yuan and Qing dynasties. In the contemporary Sinophone world, some typical phenomena might belong to the de-sinicized movements. Since 1997, the increasing presence of Mandarin-speakers in Hong Kong and expectations of mainland Chinese for Hong Kong residents to know it has caused conflicts and defensive measures by the citizens to protect Cantonese against the encroachment of Mandarin [24]. This political linguistic view has also spread among Overseas Chinese communities, the majority of which are historically Cantonese-speaking [25]. In Taiwan in 2002, the department of education, under the Chen Shuibian administration, chose to invent its own Romanization system for Mandarin Chinese, "Tongyong Pinyin”, designed by a Taiwanese scholar rather than adopting the internationally well-known "Hanyu Pinyin" system developed by PRC and used in other countries such as Singapore and Malaysia. In 2003, the government abolished the longstanding policy of using Mandarin as the sole language of government, which in practice promoted the second-largest dialect on the island, Hokkien, to fulfil many of the functions of a national language ([26]: pp. 49-58). As of 1 January 2009, "Tongyong Pinyin" was abolished by the government in favour of "Hanyu Pinyin" ([27]: p. 109).

\subsection{Monopolization or Diversification? The Nurtured ELF + CLF versus the Natural VDL}

Monopolization of ELF followed the process of Westernization, especially accompanied with the projective power of the Anglophone culture throughout the globe. The standardization of English is the apparent approach to boost the process. Standard English refers to whatever form of the English language is accepted as a national norm in any English-speaking country [28]. Unlike the case of CLF and other standard languages, no official or central regulating body defines Standard English that, without doubt, reduces the obstacles of English spreading within those unfriendly cultures to the Anglophone world and produces the varieties of Englishes. And more importantly, the varieties of Englishes are just the infrastructures of ELF. Interestingly, the unofficial Standard English has been regulated by the educational bureaucracies within the sphere of PRC in the form of governmental policies. The second approach to spreading ELF was by means of mass media. The well-known media for English learners in China are the $\mathrm{BBC}, \mathrm{VOA}$ and the others, which typically carry the mainstream culture of Anglophone as well as authentic and authoritative English language, to which, Chinese governments always keep a sharp lookout except for the linguistic materials being selected. The third approach to spread ELF was to build the certification system. IELTS, TOEFL, BEC, GRE and SAT have gradually been recognized and accepted within the sphere of PRC, from the eastern areas to the western and from the metropolis to the countryside. The certificating activities 
are challenged by and cooperated with CET, PRETCO, TEM, PETS and NPET that are controlled by the educational and personnel Ministries of PRC. Consequently, it is ELF, not EFL that has been widely spread and standardized in PRC.

When supporting the spread of ELF, CLF has been continuously forced to spread within the sphere of PRC. According to the "Law of the People's Republic of China on the Standard Spoken and Written Chinese Language" [29], the standard spoken and written Chinese language means "Putonghua" (a common speech with pronunciation based on the Beijing dialect) and the standardized Chinese characters. And the term "Putonghua" was defined in October 1955 by the Minister of Education Department in mainland China as follows: "Putonghua is the common spoken language of the modern Han group, the lingua franca of all ethnic groups in the country. The standard pronunciation of Putonghua is based on the Beijing dialect, Putonghua is based on the Northern dialects (varieties), and the grammar policy is modeled after the vernacular used in modern Chinese literary classics." [29] The case of standard Chinese implies that those varieties and dialects of Han language with non-Beijing dialect pronunciation and with non-Northern dialects vocabulary and with non-modern Chinese literary classics grammar are excluded, let alone the minority ethnic languages. The levels of Putonghua or CLF, for native and non-native speakers (HSK) in PRC, need certification. By these, CLF occupied the predominant position within the sphere of PRC and beyond, while the abundance of non-Putonghua Chinese, being deemed as non-standard and even as regionalism, would be trimmed.

Under the circumstances of the dual lingua franca, ELF as the symbol of cultural authority around the world and CLF as the legal status of the national language, VDL and the Sinitic subcultures have been heavily marginalized, some of which, even to be in imminent danger. The marginalization of VDL and the relevant sub-cultures lies in one of the rejective mechanisms among the Sinitic cultural ecology: the alliance of the dual lingua franca of CLF and ELF in the context of China: 1) the rejective path of CLF and ELF is the same; and 2) EFL, not ELF, has been controlled and parted from the cultures by the CLF system, and as such, roughly spread only as a lingua franca.

\subsection{CLF + VDL versus ELF, Sinicization or Westernization?}

The Sinocentric model of political relations and Sinocentric belief in cultural superiority (especially against the West) came to an end in the 19th century. In modern Chinese foreign policy, the PRC has stated repeatedly that it will never seek hegemony, but, some believe there are many Chinese who still hold Sinocentric beliefs [30]. Among the current cultural, political and popular context in PRC, Sinocentrism is often related to Chinese nationalism and patriotism that focus primarily on the idea of a unified, cohesive, and powerful Chinese nation, as one of the nations of the world whenever dealing with the disputes and clashes of the internal ethnic minority and regional split in Xinjiang, Tibet, Hong Kong and Taiwan. As one policy of Chinese nationalism, forcefully spreading 
CLF within the sphere of PRC was loaded in the Constitution (1982). In 2012 and 2013, the president Xi Jinping proclaimed that the Chinese Dream of the great Sinitic Nation's rejuvenation will be realized in the 21 st century step by step.

The combination of CLF with VDL generally is seen as cohesion of the Sinitic culture. Among the cultural ecology, the Han ethnic language and culture form the body while the other minority ethnic languages and cultures are affiliated with it. Borrowed from the Soviet analyses of English as the language of world capitalism and world domination, linguistic imperialism has been denunciated, according to the finding by Robert Phillipson ([31]: p. 36). Linguistic imperialism reflects and manifests cultural imperialism. As such, from the beginning, the spread of English and the relevant cultures has been supervised and controlled within the sphere of PRC, though English was determined to be learned and taught as the main foreign language by the government documents. Phillipson defines English linguistic imperialism as, the dominance asserted and retained by the establishment and continuous reconstitution of structural and cultural inequalities between English and other languages, ([31]: p. 47) not only in the period of colonialism but also in the settings of post-colonialism and neo-colonialism.

The attempt to divert the spread of English from a foreign language to a lingua franca, aiming at splitting the connection with the West culture within the sphere of PRC, has been frustrated. Under the background of globalization and cultural universalism, specifically impacted by the strong Anglophone culture, the cultural cringe has arisen gradually in PRC, especially in Taiwan, Hong Kong and any Sinophone communities around the world. Cultural inferiority complex and cultural alienation has somehow existed, not only connected with the concept of colonial mentality but also linked to self-colonial mentality. To resist the negative impacts of English and Western cultures, mainly of capitalist ideology, a series of measures and policies have been adopted and executed in PRC. For a time, nongovernmental communications had almost been banned; and later, the cultural policies to the penetrations of cultural imperialism, which is often referred to the proliferation of Western (specifically American) moral concepts, cultural products, and political beliefs around the world, have been adjusted to restraint. All the process of the clashes between Sinitic culture (including the languages) and Western culture is officially named as Sinicization, repelling Westernization or Americanization.

\section{Conclusions}

The main finding and contribution of this research are that underlying the current Sinitic cultural morphology, three linguistic-cultural circles may be revealed; and the dynamic evolution of the three circles obeys the rule of two reciprocal mechanisms.

Within the modern Sinitic cultural field, there exist 3 linguistic-cultural circles: 
ELF, as a universal language around the world, tempting to surpass the essences of the first and second language, reflects cultural universalism (mainly Westernization, specifically Americanization); CLF, originating from and surpassing the northern diversity of Han language and acting as a regional lingua franca, represents the mainstream/dominant culture; and VDL, rooting in the local, indigenous and vernacular history and reality of the Sinophone communities, manifest the multi-layers and the varieties of subcultures, or multi-culturalism of the Sinitic civilization. The three lingual-cultural dimensions constitute the dynamic structure of Sinitic cultural patterns.

The violent fluctuation of Sinitic cultural ecology follows two mechanisms: the assimilative and the rejective that determine the regenerative paradigm of Sinitic cultural morphology. The assimilative mechanism among the three dimensions was demonstrated as: 1) ELF + CLF = Chinglish (Xinhua style English) which means the compatibility of Chinese mainstream culture and cultural universalism; 2) ELF + VDL = Chinese pidgin Englishes that presents tolerance, even acceptance between the strong culture/society around the globe and sub-cultures of the Sinitic civilization; and 3) CLF + VDL = the variant nonstandard Mandarins that implies the recognition and cohesion of the sub-cultures toward the mainstream/dominant culture of the Sinitic civilization and political unification. The rejective mechanism among the three circles could be seen as: 1) CLF versus ELF + VDL, contains the Sinitic culture in its singular sense competing with the Sinitic cultures in its plural sense; 2) ELF + CLF versus VDL, implies the dual universalism within the globe and the Sinophone community attempting to restrict the diversification of Sinitic subcultures; and 3) CLF + VDL versus ELF pronounces nationalism and the cohesion of the Sinitic civilization resisting universalism and the monopolization of Americanization or Westernization.

In the modern course of the Sinitic cultural evolution, ELF owns the powerful projection of cultural universalism and globalization, CLF (modern Han language) cherishes the spiritual, institutional and economic powers of the Red regime, and VDL plants into society and history. The three lingual-cultural dimensions interact with the others that reshape the current morphology of Sinitic cultural ecology. The counterpoise of the three dimensions is the apparent feature of the regenerative paradigm of Sinitic culture, and the imbalance causes the violent split of Sinitic culture.

However, the research only offers an evolutional framework of current Sinitic cultural ecology, the finding and the mechanism still need to be supported by further empirical and quantitive (big data) research.

\section{Conflicts of Interest}

The authors declare no conflicts of interest.

\section{References}

[1] Kachru, Y. and Nelson, C.L. (2006) World Englishes in Asian Contexts. Hong Kong University Press, Hong Kong. 
[2] Lam, A. (2002) English in Education in China: Policy Changes and Learners' Experiences. World Englishes, 21, 245-256. https://doi.org/10.1111/1467-971X.00245

[3] McArthur, T. (2002) Oxford Guide to World English. Oxford University Press, New York.

[4] Huntington, S. (1996) The Clash of Civilizations and the Remaking of World Order. Simon \& Schuster, New York.

[5] Norman, J. (1988) Chinese. Cambridge University Press, Cambridge.

[6] Norman, J. (2003) The Chinese Dialects: Phonology. In: Thurgood, G. and LaPolla, R.J., Eds., The Sino-Tibetan Languages, Routledge, London, 72.

[7] DeFrancis, J. (1984) The Chinese Language: Fact and Fantasy. University of Hawaii Press, Honolulu. https://doi.org/10.1515/9780824840303

[8] Mair, V. (1991) What Is a Chinese "Dialect/Topolect"? Reflections on Some Key Sino-English Linguistic Terms. Sino-Platonic Papers, 29, 6.

[9] Taiwan.cn (2015) China-Taiwan History of Taiwan Area (Chinese). http://www.taiwan.cn/twrwk/twdq/xgjg/200603/t20060306_606.htm

[10] Falkenhausen, L. (1999) The Waning of the Bronze Age: Material Culture and Social Developments, 770-481 B.C. In: Loewe, M. and Shaughnessy, E.L., Eds., The Cambridge History of Ancient China: From the Origins of Civilization to 221 B.C., Cambridge University Press, Cambridge, 544.

https://doi.org/10.1017/CHOL9780521470308.009

[11] Wurm, S.A., Li, R., Baumann, T. and Lee, M.W. (1987) Language Atlas of China. Longman, London.

[12] Ramsey, R. (1987) The Languages of China. Princeton University Press, Princeton.

[13] Ethnologue.com (2015) Ethnologue/China. http://www.ethnologue.com/country/CN

[14] Mair, V. (2009) Protests, Complaints, and Representations. Language Log, 29 July.

[15] Lavin, A. (2008) Feudal to Translate. Weekly Standard, 31 March.

[16] Baker, P. and Mühlhäusler, P. (1990) From Business to Pidgin. Journal of Asian Pacific Communication, 1, 100.

[17] Kim, R.I. (2008) California Chinese Pidgin English and Its Historical Connections: Preliminary Remarks. Journal of Pidgin and Creole Languages, 23, 329-339. https://doi.org/10.1075/jpcl.23.2.08kim

[18] Siegel, J. (2009) Chinese Pidgin English in South-Eastern Australia: The Notebook of Jong Ah Siug. Journal of Pidgin and Creole Languages, 24, 306-337. https://doi.org/10.1075/jpcl.24.2.04sie

[19] Meierkord, C. (2002) "Language Stripped Bare" or "Linguistic Masala"? Culture in Lingua Franca Conversation. In: Knapp, K. and Meierkord, C., Eds., Lingua Franca Communication, Peter Lang, Frankfurt, 109-133.

[20] House, J. (2002) Developing Pragmatic Competence in English as a Lingua Franca. In: Knapp, K. and Meierkord, C., Eds., Lingua Franca Communication, Peter, Frankfurt am Main, 245-267.

[21] Hülmbauer, C. (2007) "You Moved, Aren't?" The Relationship between Lexicogrammatical Correctness and Communicative Effectiveness in English as a Lingua Franca. Views. Vienna English Papers, 16, 3-35.

[22] Thomas, G. (1991) Linguistic Purism. Longman, New York.

[23] Gernet, J. (1996) A History of Chinese Civilization. Cambridge University Press, Cambridge. 
[24] Luo, C. (2013) City University Students Deny Teacher Took Class in Mandarin. South China Morning Post, 14 October.

http://www.scmp.com/news/china-insider/article/1331396/city-university-studentsdeny-teacher-took-class-mandarin?comment-sort=recommended

[25] Wesmcl (2014) China, Hong Kong and Cantonese: Dialect Dielectric. China Daily Mail, 10 July 2014, 4.

https://chinanews.net.au/2014/07/10/china-hong-kong-and-cantonese-dialect-diale cticl

[26] Hao, Z.D. (2010) De-Sinicization under Lee and Chen and the Role of Intellectuals. In: Whither Taiwan and Mainland China? National Identity, the State, and Intellectuals, Hong Kong University Press, Hong Kong, 49-58.

https://doi.org/10.5790/hongkong/9789622091009.003.0004

[27] Hebert, D. and Kertz-Welzel, A. (2012) Patriotism and Nationalism in Music Education. Ashgate Publishing, Farnham, 109.

[28] Thorne, S. (1997) Mastering Advanced English Language. Palgrave Macmillan, Basingstoke. https://doi.org/10.1007/978-1-349-13645-2

[29] Law of the People's Republic of China on the Standard Spoken and Written Chinese Language (Order of the President No. 37, 2005).

[30] Chinanews.com. 11 June 2011.

http://www.chinanews.com/gn/2011/06-11/3104748.shtml

[31] Phillipson, R. (1992) Linguistic Imperialism. Oxford University Press, Oxford. 